\title{
BLAUWE GOLF, TAKEUCHI SEIHO
}

Het naturalisme was rond 1900 al stevig geworteld in de Japanse schilderkunst. Het begin van de beweging wordt meestal gelegd bij Maruyama Okyo (1733-95), die vanaf het midden van de $18^{\mathrm{e}}$ eeuw elementen uit de Chinese en Europese schilderkunst ging combineren met de technieken die hij had geleerd tijdens zijn opleiding in de Japanse Kano-stijl schilderkunst. ${ }^{1}$ Hij ontwierp perspectief-prenten op basis van Chinese prenten uit Suzhou (die op hun beurt weer waren gebaseerd op Europese voorbeelden), kopieerde Chinese schilderingen van vogels en planten en bestudeerde Europese anatomieboeken voor het afbeelden van mensfiguren. Op basis van die mengelmoes aan inspiratiebronnen componeerde hij zijn vernieuwende, eigen stijl. Schetsen naar de natuur stond centraal, om werken te kunnen maken die waren gebaseerd op observatie in plaats van verbeelding. Okyo was een bijzonder succesvolle kunstenaar en zijn vele leerlingen en navolgers zorgden ervoor dat er in de $19^{\mathrm{e}}$ eeuw een bloeiende naturalistische traditie werd gevestigd. De Chinese en Europese invloeden waren toen zozeer verwerkt, omgevormd en ingebed in het repertoire dat het naturalisme niet langer als een vreemde eend in de Japanse bijt mag worden beschouwd.

Dankzij een bescheiden reeks aanwinsten in de laatste jaren van zowel Vereniging als Rijksmuseum kan het naturalistische spoor door de geschiedenis van de Japanse schilderkunst al aardig zichtbaar worden gemaakt. U zult zich misschien de tentoonstelling in het museum CODA in Apeldoorn uit 2007 herinneren, waar dit thema een van de onderwerpen was. ${ }^{2}$ De aanwinst die hier gepresenteerd wordt (afb. 1) is een nieuwe, vroeg $20^{\mathrm{e}}$-eeuwse schakel in dat verhaal.

Takeuchi Seiho (1864-1942) was met recht een erfgenaam van Okyo: “[...] een schilder moet meer schilderen dan hij spreekt, meer denken dan hij schildert, en meer rustig de natuur observeren dan hij denkt", zo formuleerde hij het. ${ }^{3}$ Nauwgezette bestudering moest leiden tot een grondig begrip en een rake typering van de essentie van een natuurscène. Dat adagium is zeker van toepassing op deze schildering. Seiho moet lang gestaard hebben naar golven die op de rotskust sloegen, voordat hij de Blauwe golf op de zijde heeft gezet. Water vloeit over een zwarte rots, terwijl het water van de volgende golf alweer hoog opspat. Beide fenomenen zijn natuurlijk notoir lastig weer te geven en de schildering kan dan ook als een krachtproef voor de kunstenaar worden gezien, gemaakt in 1905 toen Seiho 41 of 42 jaar was en in een cruciale fase van zijn kunstenaarschap was gekomen. Zijn talent had hij toen al bewezen. Hij was een gerespecteerd kunstenaar, in bezit van zijn eigen atelier met leerlingen en docent aan de Stedelijke School voor Kunst en Kunstnijverheid in Kyoto. 
In 1900 en 1901 had Seiho een reis van zes maanden naar Europa gemaakt. ${ }^{4}$ Via Parijs was hij naar Londen, Antwerpen en Amsterdam gegaan, al schetsend in de dierentuinen, waar vooral leeuwen zijn aandacht hadden. In Japan waren er op dat moment nog geen leeuwen en er wordt gezegd dat Seiho ze wekenlang heeft bestudeerd en getekend. Verder was hij onder de indruk van het werk van William Turner (1775-1851) en Jean Baptiste Corot (17961875), terwijl hij zich ook persoonlijk met de oriëntalist Jean Léon Gérôme (1824-1904) schijnt te hebben onderhouden over het schilderen van dieren. $\mathrm{Na}$ terugkomst signeerde hij voortaan met een aangepast karakter voor sei, dat het karakter voor 'West' in zich draagt. Seiho voelde zich beïnvloed door

Afb 2.

Ganryo, (detail van) Zeearend op een rots aan de kust, Schildering gekleurde inkt op papier, $163 \times 363 \mathrm{~cm}$. Japan, ca. 1840, Rijksmuseum, inv.nr. AK-MAK-1721-A/B zijn Europese ervaringen en dat is te zien in zijn werk van de jaren erna. Mistige partijen weerspiegelen Turners atmosferische landschappen en een uitgebreide reeks van leeuwenschilderingen maakte in Japan furore om de inderdaad indrukwekkende levensechtheid. Dit 'Westers realisme' heeft ertoe geleid dat Seiho wel een 'Westerse-stijl kunstenaar' genoemd is. ${ }^{5}$ Het lijkt me zeker dat Seiho zich heeft laten inspireren door wat hij tegenkwam in Europa, maar wie zijn hele oeuvre aan het oog voorbij laat trekken ziet toch voornamelijk de Japanse naturalistische traditie als doorlopende lijn.

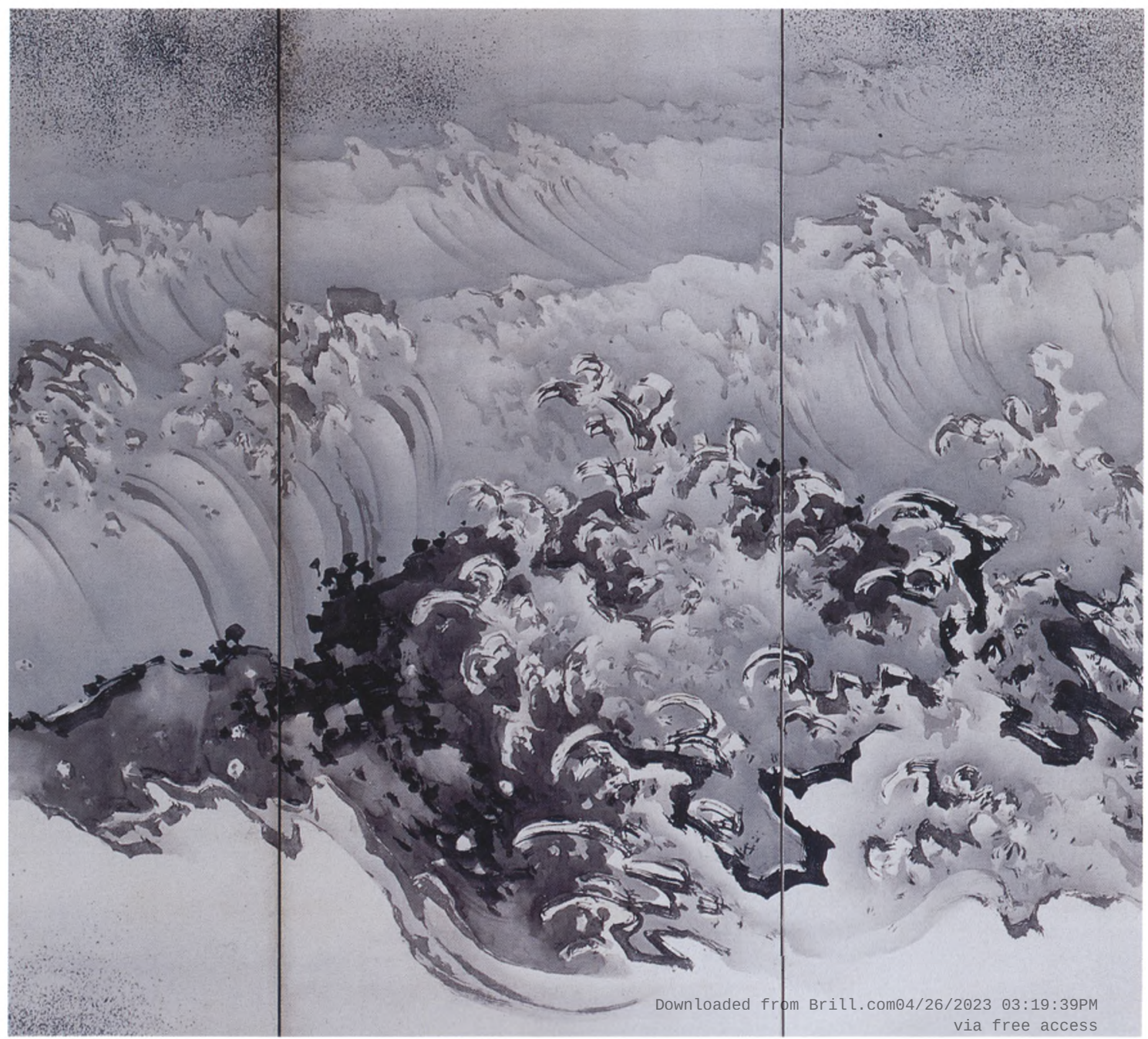


De Blauwe golf, vier jaar na zijn Europareis geschilderd, mag daarvan getuigen. Vergelijking met een ander werk uit de Verenigingscollectie, het indrukwekkende paar kamerschermen van Ganryô (afb. 2) illustreert de traditie op basis waarvan Seiho de schilderkunst een nieuwe draai heeft gegeven. ${ }^{6}$ Beiden zien in het naturalisme een manier om de essentie van de natuur te vatten. Ganryô laat de kracht van de branding tot uiting komen door middel van intense, haast nerveuze penseelstreken. Seiho's lijnvoering is wat gepolijster, maar de energie van het water is ook hier goed voelbaar. Meer nog dan bij Ganryô lijkt het een echte momentopname te zijn, alsof het een foto is waarop de druppels in de vlucht zijn bevroren. Om kort te gaan, hier toont zich in alle glorie het razend scherpe, tot grote hoogte ontwikkelde waarnemingsvermogen waar Seiho zo de nadruk op legde.

Niet mis, zo'n fraaie schildering, in goede staat en mooi compleet met door de kunstenaar zelf gesigneerde en gedateerde houten doos, op zijn beurt weer gevat in een gelakte buitendoos. We popelen om deze schildering in het echt aan u voor te stellen, straks in het Paviljoen.

\section{Literatuur}

Ellen P. Conant, Nihonga: Transcending the Past: Japanese-Style Painting, 1868-1968, Tokyo, 1995.

Menno Fitski, 'Schilderingen', Aziatische Kunst 37/2 (2007), pp. 3-15

Patricia Graham, 'Maruyama Okyo', in: J. Turner (red.), The Dictionary of Art, Deel 23, New York, 1996, pp. 522-3.

Eric van den Ing, 'One of Seiho's lions', Andon 61 (1999), pp. 3-13.

Laurance P. Roberts, A Dictionary of Japanese Artists.

\section{Noten}

1. De Kano-school is een van oorsprong Chinese stijl van inktschilderkunst, die in Japan de geëigende stijl van de militaire elite werd. Kenmerkend zijn de monochrome landschapsschilderingen en de afbeeldingen van dieren en bomen tegen een achtergrond van goudfolie. De leermeester van Okyo, Ishida Yutei (1721-86), wordt tot de Kano-schilders gerekend, maar zijn werk verraadt ook invloeden uit de Tosaen Rinpa-tradities. Het is dus niet verwonderlijk dat Okyo zich vrij voelde om zich door meerdere schilderstijlen te laten inspireren. Zie voor een samenvatting van Okyo's carrière Graham 1996: 522-3.

2. Zie Fitski 2007: 3-15.

3. Conant 1995: 322-3.

4. Voor een overzicht van de Europareis zie Van den Ing 1999: 3-13.

5. Zie bijvoorbeeld Roberts 1976: 171 .

6. De hele schermen staan afgebeeld in Aziatische Kunst 2007-2: 8-9. 